\title{
Caracterização da poligalacturonase produzida por fermentação semi-sólida utilizando-se resíduo do maracujá como substrato ${ }^{1}$
}

\author{
Rosane L. A. de Souza ${ }^{2}$, Líbia de S. C. 0 liveira $^{3}$, Flávio L. H. da Silva ${ }^{3}$ \& Beatriz C. Amorim ${ }^{4}$
}

\section{RESU MO}

As enzimas pectinolíticas ou pectinases são um grupo heterogêneo de enzimas que hidrolisam as substâncias pécticas presentes nas células vegetais. Essas enzimas estão sendo aplicadas em diversas áreas tornando-se importante conhecer suas características visando uma aplicação eficiente. Assim, este trabalho, objetivou-se caracterizar o resíduo seco da casca e do albedo do maracujá (Passiflora edulis) e posterior caracterização da enzima poligalacturonase, produzida através da fermentação em estado sólido e, como agente da fermentação, o fungo filamentoso Aspergillus niger. 0 resíduo do maracujá apresenta teor de pectina de 13,10\%. A atividade de poligalacturonase alcançou um pico em $66 \mathrm{~h}$ de processo, para $40 \%$ de umidade inicial e $1 \%$ da concentração da fonte de nitrogênio, condição, em que a atividade obtida foi de $20,9 \mathrm{U} \mathrm{g}^{-1}$. A poligalacturonase do extrato enzimático bruto apresentou boa estabilidade térmica até temperaturas de $50^{\circ} \mathrm{C}$. Esta enzima permaneceu estável para pH entre 3,5 e 5,5 e não foi detectada para valores de $\mathrm{pH}$ acima de 6,5.

Palavras-chave: Passiflora edulis, pectinases, Aspergillus niger, pectina

\section{Characterization of polygalacturonase produced by solid-state fermentation using the residue of passion fruit as substrate}

\begin{abstract}
Pectinolytic enzymes, or pectinases, are a heterogeneous group of enzymes that hydrolyze the pectic substances present in plant cells. These enzymes are applied in several areas, making it important to know their characteristics for an efficient application. This work aimed to characterize the dry residue of passion fruit (Passiflora edulis) and subsequent characterization of the enzyme polygalacturonase produced by solid state fermentation and leavening agent and the filamentous fungus Aspergillus niger. The residue of passion fruit presented a pectin content of $13.10 \%$, having a potential as a substrate for the production of pectinases. The activity of polygalacturonase reached a maximum value after $66 \mathrm{~h}$ of process with $40 \%$ initial moisture content and $1 \%$ of nitrogen supplementation. In this condition an activity of $20.9 \mathrm{U} \mathrm{g}^{-1}$ was obtained. The polygalacturonase produced the crude enzymatic extract presenting good thermal stability up to temperatures of $50^{\circ} \mathrm{C}$. This enzyme remained stable in the $\mathrm{pH}$ range between 3.5 and 5.5 and was not detected for $\mathrm{pH}$ values above 6.5 .
\end{abstract}

Key words: Passiflora edulis, pectinases, Aspergillus niger, pectin

\footnotetext{
1 Parte da Dissertação do primeiro autor ao Curso de Pós-Graduação em Engenharia Q uímica da UFCG

2 Mestre em Engenharia Q uímica. Fone: (83) 3310-1521. E-mail: rosaneliege@yahoo.com.br

3 UAEQ/UFCG, Av. Aprígio Veloso, 882, Bodocongó, CEP 58109-900, Campina Grande, PB. Fone: (83) 3310-1115. E-mail: libiac@deq.ufcg.edu.br; flhs@deq.ufcg.edu.br

${ }^{4}$ Mestranda em Engenharia Química. PPGEQ/UFCG. Fone: (83) 3310-1521. E-mail: bia_eq@yahoo.com.br
} 


\section{INTRODUÇÃO}

As enzimas pectinolíticas ou pectinases, hidrolisam as substâncias pécticas sob diferentes mecanismos de reação, pela preferência de substrato (pectina, ácido péctico ou protopectina), transeliminação, hidrólise ou clivagem, a qual pode ser randômica, pela ação de endoenzimas, ou terminal, por exoenzimas (Uenojo, 2003; Kashyap et al., 2001).

Existem três tipos de pectinases. O primeiro grupo, constituído por pectinaesterases, remove os grupos metil-éster, ao passo que as protopectinases agem solubilizando a protopectina. Finalmente, as despolimerases catalisam a quebra das ligações glicosídicas existentes entre substâncias pécticas (Jayani et al., 2005; Uenojo, 2003).

A poligalacturonase (PG) é apontada como a principal enzima despolimerase. As poligalacturonases fúngicas são úteis por sua alta atividade enzimática e ótimas em região levemente ácida (Zheng \& Shetty, 2000). Cada enzima tem em particular, uma finalidade específica, por exemplo, a poligalacturonase é utilizada no preparo de alimentos para bebês (Gummadi \& Panda, 2003).

A principal aplicação dessas enzimas está na indústria de processamento de sucos sendo, portanto, usadas nas etapas de extração, clarificação e concentração (Martin, 2006). Além disso, fazem parte também em processos fermentativos de café e chá, tratamento de resíduos vegetais e extração de óleos (Uenojo \& Pastore, 2007). Recentemente, tem surgido o tratamento de fibras naturais, por exemplo as fibras da banana, com extrato bruto de pectinases produzidas por Streptomyces lydicus, para uso em indústrias têxteis e de papel (Nicemol et al., 2008)

A caracterização enzimática é importante para conhecer particularidades como termoestabilidade e resistência ao pH, informações relevantes para a aplicação industrial e que serão necessárias para manter o nível desejado de atividade da enzima por um longo período de tempo. A estabilidade de pectinases é afetada por parâmetros físicos, entre eles $\mathrm{pH}$ e temperatura, e químicos, como inibidores ou indutores (Gummadi \& Panda, 2003). Zheng \& Shetty (2000) verificaram que as pectinases podem ser utilizadas nos processos de extração e clarificação de sucos sem que sofram perda considerável da sua atividade já que o pH natural de frutas, tecidos vegetais e sucos, é ácido.

Com relação às técnicas de fermentação, a fermentação em estado sólido (FES) geralmente é preferida por permitir a produção de enzimas brutas mais concentradas e, consequentemente, com menores custos de extração e purificação (Silva et al., 2002). O estudo de Ustok et al. (2007), aponta rendimento maior no que diz respeito á atividade poligalacturonásica utilizando-se a fermentação em estado sólido do que a fermentação submersa. O processo de FES estimula as condições de crescimento de vários fungos filamentosos já que o meio se aproxima do habitat natural desses micro-organismos (Hölker \& Lenz, 2005).

Os substratos para fermentação semi-sólida, em geral resíduos ou subprodutos da agroindústria, têm como principais componentes celulose, hemicelulose, lignina, amido, pectina e proteínas, o que os caracteriza como materiais extre- mamente heterogêneos e que atuam tanto como fonte de carbono e energia quanto de suporte para o crescimento microbiano (Pandey, 2003).

Pinto et al. (2006) relatam que farelos, cascas, bagaço de frutas da agroindústria (maça, maracujá, pedúnculo de caju) e outros, são materiais considerados viáveis para a biotransformação. Segundo Otagaki \& Matsumoto (1958) a casca do maracujá amarelo desidratada apresenta $4,60 \%$ de proteínas e $20,00 \%$ de pectina. Abud et al. (2007) obtiveram 9,01\% de pectina na casca, albedo e sementes do maracujá. A pectina, além do efeito indutivo, favorece a excreção de pectinases pelos fungos produtores.

A produção de maracujá no Brasil se encontra à frente de outros países, como Peru, Venezuela, África do Sul, Sri Lanka e Austrália. A produção brasileira de maracujá esteve, no ano de 2007, em torno de 664.286 ton, com rendimento de $14 \mathrm{t} \mathrm{ha}^{-1}$. Neste período, a região Nordeste respondeu por $63 \%$ da produção nacional (IBGE, 2009). Um aspecto importante sobre esse tipo de material é que a casca do maracujá constitui cerca de $53 \%$ do peso total do fruto, sendo geralmente desperdiçada.

Neste trabalho se realizou a caracterização da casca e do albedo do maracujá para produção de poligalacturonase por fermentação semi-sólida utilizando-se, como agente da fermentação, o fungo filamentoso Aspergillus niger mutante CCT 0916. Além disso, foram analisadas a estabilidade da enzima frente ao $\mathrm{pH}$, e a temperatura.

\section{MATERIAL E MÉTODOS}

\section{Micro-organismo}

O micro-organismo utilizado foi o fungo filamentoso da linhagem Aspergillus niger mutante CCT 0916, pertencente à coleção da Embrapa Agroindústria Tropical (Fortaleza, CE). A cepa escolhida foi transportada em tubos de ensaio contento solo estéril e estocados a $-18{ }^{\circ} \mathrm{C}$.

\section{Meio de cultivo}

Utilizaram-se o resíduo da casca e o albedo do maracujáamarelo (Passiflora edulis f. flavicarpa), semimaduro, adquirido na EMPASA (Empresa Paraibana de Abastecimento e Serviços Agrícolas) em Campina Grande, Paraíba, Brasil. A casca e o albedo foram separados da polpa e secados em estufa com circulação de ar a $55{ }^{\circ} \mathrm{C}$, por aproximadamente 15 h. O resíduo seco foi moído e armazenado em recipientes de vidro herméticos, a temperatura ambiente.

\section{Caracterização}

Realizaram-se, para a caracterização do resíduo, as análises de $\mathrm{pH}$, cinzas, umidade, densidade aparente, densidade real, porosidade, distribuição granulométrica, açúcares redutores, pectina e proteína.

A determinação de $\mathrm{pH}$, cinzas e umidade, foi realizada segundo metodologia descrita em Brasil (2005).

Para a densidade aparente foram pesados $100 \mathrm{~g}$ do material em proveta, sem compactação, para determinação do volume ocupado. Obteve-se o valor da densidade aparente 
mediante a aplicação da Eq. 1.

$$
\text { densidade aparente }=\frac{\text { massa, } \mathrm{g}}{\text { volume ocupado, } \mathrm{cm}^{3}}
$$

A densidade real do resíduo seco foi determinada a partir da relação entre a massa e o volume da amostra, através do deslocamento de um líquido de óleo de cozinha em proveta.

$$
\text { densidade real }=\frac{\text { massa, } \mathrm{g}}{\left(\mathrm{V}_{2}-\mathrm{V}_{1}\right), \mathrm{cm}^{3}}
$$

A densidade real foi determinada pela Eq. 2 .

A porosidade foi determinada conforme a Eq. 3 (Keey, 1991).

$$
\text { porosidade }=1-\frac{\text { densidade aparente }}{\text { densidade real }}
$$

Fez-se a distribuição granulométrica utilizando-se $100 \mathrm{~g}$ do material colocados em conjunto de peneiras Produteste com 14, 20, 24, 35, 48 e 60 mesh e agitados na frequência 9 do agitador mecânico, pelo tempo de $20 \mathrm{~min}$, conforme a NBR-7181 (ABNT, 1984).

Realizou-se a quantificação dos grupos redutores com base na redução do ácido 3,5 dinitrosalicílico a 3-amino-5-nitrosalicílico (DNS), simultaneamente com a oxidação do grupo aldeído do açúcar a grupo carboxílico. O procedimento adotado foi o descrito por Miller (1959) com modificações realizadas por Correia (2004).

A determinação de pectina foi baseada no procedimento de Rangana (1979).

Determinou-se o teor de proteína através do método semimicro Kjeldahl com adaptação para UV-visível a $410 \mathrm{~nm}$, de acordo com a metodologia de Silva (1998).

\section{Processo fermentativo}

O processo foi realizado em Erlenmeyer de $250 \mathrm{~mL}$ contendo $10 \mathrm{~g}$ do resíduo úmido. A umidade inicial do meio foi ajustada em $40 \%$ (b.u) o que representa uma atividade de água de 0,933 . Realizou-se a suplementação do substrato com a fonte adicional de nitrogênio através de sulfato de amônio na concentração de $1,0 \%\left(\mathrm{~m} \mathrm{~m}^{-1}\right)$. Os frascos erlenmeyers foram fechados com tampão de algodão envolvido com gaze e autoclavados por $5 \mathrm{~min}$ a $0,5 \mathrm{~atm}$. Os conídios foram ativados em duas etapas, usando-se um meio básico composto por pectina cítrica $\left(10 \mathrm{~g} \mathrm{~L}^{-1}\right), \mathrm{NaNO}_{3}\left(3 \mathrm{~g} \mathrm{~L}^{-1}\right), \mathrm{KH}_{2} \mathrm{PO}_{4}$ $\left(1 \mathrm{~g} \mathrm{~L}^{-1}\right), \mathrm{MgSO}_{4}\left(0,5 \mathrm{~g} \mathrm{~L}^{-1}\right), \mathrm{KCl}\left(0,5 \mathrm{~g} \mathrm{~L}^{-1}\right), \mathrm{FeSO}_{4} 7 \mathrm{H}_{2} \mathrm{O}$ $\left(0,01 \mathrm{~g} \mathrm{~L}^{-1}\right)$ e Agar-agar $\left(20 \mathrm{~g} \mathrm{~L}^{-1}\right)$ sendo transferidos do solo para este meio com alça de platina e incubados por cinco dias em estufa a $30{ }^{\circ} \mathrm{C}$, este meio foi denominado primeiro repique. Partindo-se deste repique, obteve-se o segundo repique. Os esporos do segundo repique foram utilizados para obtenção de grande quantidade de esporos no meio de sabugo de milho. Cada repique pôde ser mantido sob refrigeração por um período de quatro meses e, seguindo-se este procedimento, cada suspensão de conídios no solo somente pôde ser usada 4 ou 5 vezes e depois descartada (Couri \& Farias,
1995). Nos frascos de sabugo com esporos foram adicionados $40 \mathrm{~mL}$ de solução 0,3\% v/v de Tween; após agitação os esporos foram transferidos para Erlenmeyer estéril com auxílio de gaze estéril. A quantificação da suspensão obtida foi feita através de contagem dos esporos em Câmara de Neubauer espelhada. $\mathrm{O}$ volume de suspensão de esporos adicionado ao meio de fermentação foi ajustado de modo a se ter um inóculo de $10^{7}$ esporos por g de substrato sólido. A fermentação ocorreu em estufa a $30^{\circ} \mathrm{C}$ e umidade relativa controlada a $60 \%$. O controle da umidade relativa foi realizado mediante a evaporação de água contida em recipiente colocado dentro da estufa, sendo o nível de água restabelecido durante todo o processo. As amostras foram retiradas periodicamente durante a fermentação em $0,7,22,30,44,50$, 66, $72 \mathrm{~h}$, determinando-se a umidade, açúcares redutores (AR), $\mathrm{pH}$ e atividade de PG de cada amostra.

\section{Extração da enzima}

Para a extração do complexo enzimático, adicionaram-se 5,0 mL de tampão acetato $200 \mathrm{mM} \mathrm{pH} \mathrm{4,5} \mathrm{a} \mathrm{cada} \mathrm{g} \mathrm{de} \mathrm{meio}$ fermentado. Após homogeneização, os frascos erlenmeyers foram mantidos durante $1 \mathrm{~h}$ em banho termostático a $30^{\circ} \mathrm{C}$. $\mathrm{O}$ extrato enzimático bruto obtido foi filtrado em algodão hidrófobo de uso farmacêutico e estocado em freezer.

\section{Medida da atividade poligalacturonásica}

A atividade poligalacturonásica foi estimada pela quantificação de substâncias redutoras liberadas de solução 0,25\% $\left(\mathrm{m} \mathrm{v}^{-1}\right)$ de ácido poligalactunônico em tampão acetato

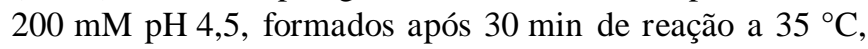
conforme Couri \& Farias (1995). Uma unidade de atividade poligalacturonásica foi definida como a quantidade de enzima que libera $1 \mu \mathrm{mol}$ de ácido galacturônico por minuto, nas condições de reação. Os ensaios foram realizados em duplicata e os resultados foram expressos em unidades de atividade por grama de meio úmido fermentado $\left(\mathrm{U} \mathrm{g}^{-1}\right)$.

\section{Efeito do pH e da temperatura na estabilidade da poligacturonase}

Para o estudo de termoestabilidade, o extrato enzimático foi incubado nas temperaturas de 10, 20, 30, 40, 50, 60, 70, 80 e $90^{\circ} \mathrm{C}$, por $20 \mathrm{~min}$ e em seguida analisado quanto á sua atividade poligalacturonásica. Para verificar o efeito do $\mathrm{pH}$ na estabilidade da poligalacturonase a enzima foi extraída com água e incubada durante $24 \mathrm{~h}$ nos seguintes tampões: $0,1 \mathrm{M}$ glicina- $\mathrm{HCl}$ para $\mathrm{pH} 2,5$; tampão acetato $200 \mathrm{mM}$ para $\mathrm{pH}$ entre 3,5-6,5; 0,1 M Tris- $\mathrm{HCl}$ para $\mathrm{pH}$ entre 7,5-8,5 e para a faixa de $\mathrm{pH}$ entre 9,5-10,5 utilizou-se $0,1 \mathrm{M}$ glicina-NaOH. Realizaram-se, após o período de incubação, os ensaios de atividade poligalacturonásica. Os resultados foram expressos em termos da atividade residual (\%).

\section{RESULTADOS E DISCUSSÃO}

\section{Caracterização do resíduo seco do maracujá}

A caracterização do resíduo seco da casca e do albedo do maracujá está apresentada na Tabela 1. As análises foram 
Tabela 1. Valores médios e desvio padrão dos parâmetros analisados na caracterização do resíduo do maracujá em base seca

\begin{tabular}{lr}
\hline Parâmetros analisados & \multicolumn{1}{c}{ Valor } \\
Umidade & $0,15 \pm 0,01$ \\
Cinzas (\%) & $6,33 \pm 0,18$ \\
Proténa total (\%) & $5,72 \pm 0,34$ \\
Pectina (\% pectato de cálcio) & $13,10 \pm 0,14$ \\
Açucares redutores (\%) & $11,71 \pm 0,46$ \\
Densidade aparente $\left(\mathrm{g} \mathrm{cm}^{-3}\right)$ & $0,40 \pm 0,00$ \\
Densidade real $\left(\mathrm{g} \mathrm{cm}^{-3}\right)$ & 1,25 \\
Porosidade & $0,66 \pm 0,50$ \\
pH & $3,57 \pm 0,20$ \\
\hline
\end{tabular}

realizadas em triplicata, com exceção da densidade real e porosidade que o foram apenas em um ensaio.

O resíduo do maracujá apresentou teor de proteína total superior ao de resíduos de algumas frutas, como mangaba, goiaba, acerola e umbu, de acordo com os dados de Abud et al. (2007).

Dartora et al. (1999), estudando diversos fungos filamentosos, inclusive Aspergillus niger na produção de pectinases e utilizando farelo de trigo como principal fonte de carbono, observaram que, adicionando-se pectina na concentração de $10 \%\left(\mathrm{~m} \mathrm{~m}^{-1}\right)$, tem-se o valor ótimo para que se perceba um efeito de indução sobre a produção da enzima.

Fontana et al. (2005) encontraram, produzindo PG por Aspergillus niger em meio á base de farelo de trigo, que até $16 \%$ a pectina pode ser adicionada sem que seja observado efeito de repressão por parte deste componente na excreção das pectinases pelo fungo produtor.

A literatura mostra que altas concentrações de açúcares no meio suprem a necessidade dos micro-organismos para seu crescimento e a pectina no meio é pouco utilizada. Porém, em condições restritivas de concentração de açúcares o metabolismo é direcionado para a quebra da molécula de pectina, de modo que possa ser consumida, levando a altas atividades pectinolíticas (Fawole \& Odunfa, 2003).

Alcântara et al. (2007) caracterizaram o resíduo do pedúnculo do caju para posterior produção de pectinases; no entanto, os autores sugeriram fazer o ajuste da concentração de açúcar e pectina. Santos et al. (2008b) relatam a produção de pectinases utilizando o mesmo substrato, porém sem adição de fonte indutora ou ajuste no conteúdo de açúcar. Quanto ao resíduo de maracujá, este apresenta características favoráveis para a produção de enzimas pectinolíticas e, portanto, neste trabalho não foi necessária a adição de pectina e açúcar ao meio.

Observa-se que o pH do resíduo é ácido $(3,57 \pm 0,20)$, possuindo as condições de $\mathrm{pH}$ adequadas para a adaptação do micro-organismo ao meio. Zheng \& Shetty (2000), determinaram que o $\mathrm{pH}$ igual a 5,00 foi considerado ótimo para a produção de PG, por Lentinus edodes. Bueno et al. (2005) sugerem a condição de $\mathrm{pH} 4,5$ para a produção de poligalacturonase pelas linhagens de Aspergillus sp CFCF-0492, Aspergillus sp CFCF-HC1 e Aspergillus sp CFCF-CC1, isoladas do solo.

A distribuição granulométrica do resíduo seco mostra que a maioria das partículas teve tamanho entre 20 e 35 mesh, o que corresponde a partículas entre 0,42 e 0,85 mm (Figura 1). Partículas de tamanho reduzido oferecem maior área superficial ao ataque microbiano, mas, ao mesmo tempo, tendem a se compactar facilmente, comprometendo a respiração e a aeração do sistema (Souza et al., 2007).

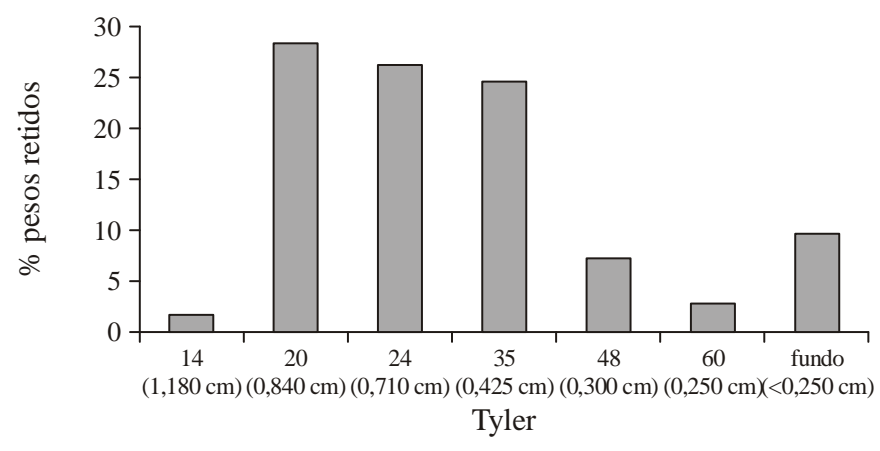

Figura 1. Distribuição granulométrica do resíduo seco do maracujá

Quando distribuídas nos reatores para a realização da FES, as partículas maiores promovem mais espaço interpartículas diminuindo, porém, o rendimento da absorção dos nutrientes pelo micro-organismo. Segundo Pinto et al. (2006), o substrato não deve apresentar aglomeração das suas partículas individuais para que o ar necessário ao desenvolvimento microbiano atravesse os espaços vazios do meio.

Apenas 10\% das partículas apresentaram tamanho menor que $0,25 \mathrm{~mm}$; Esta característica parece repercutir na alta porosidade encontrada, o que favorece a aeração do sistema disponibilizando o oxigênio necessário ao desenvolvimento do micro-organismo. Além do tamanho das partículas, a porosidade está relacionada com a densidade real do resíduo $\left(1,25 \mathrm{~g} \mathrm{~cm}^{-3}\right)$. A densidade aparente de $0,401 \mathrm{~g} \mathrm{~cm}^{-3}$ revela que o resíduo tende a não se compactar completamente gerando espaços vazios entre as partículas do resíduo, necessários à respiração e metabolismo.

A Figura 2 mostra o comportamento das variáveis analisadas na produção de poligalacturonase, com condições iniciais de $40 \%$ de umidade e $1,0 \%$ de nitrogênio.

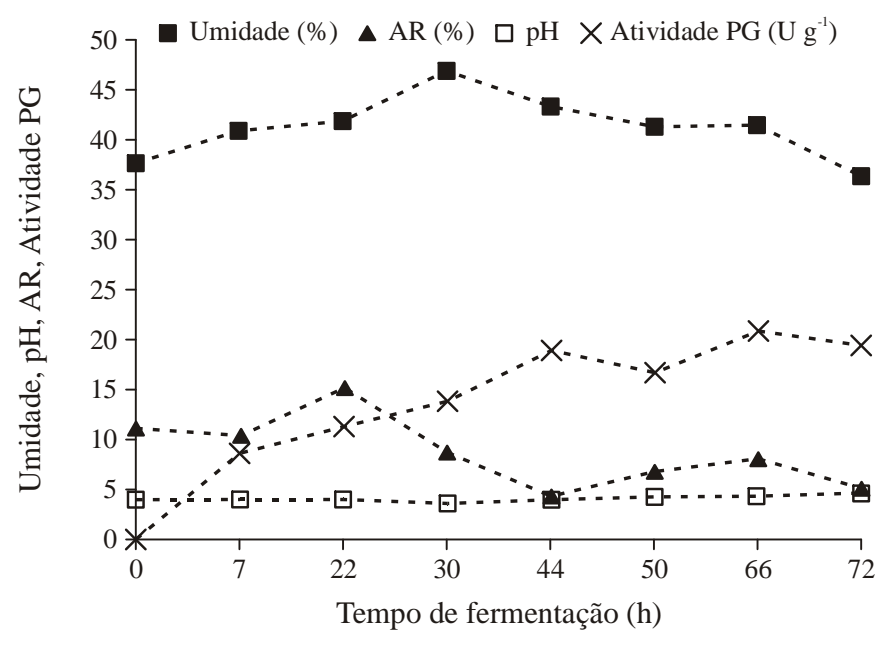

Figura 2. Acompanhamento do processo de fermentação semi-sólida por Aspergillus niger do resíduo seco do maracujá no tempo 
$\mathrm{O} \mathrm{pH}$ apresentou-se constante durante as $72 \mathrm{~h}$ de fermentação, assim como a umidade. Entre 7 e 22 h de cultivo observa-se acúmulo de açúcares redutores no meio. A velocidade de hidrólise de outros carboidratos, por exemplo a pectina, parece ser maior que a velocidade de consumo de açúcares redutores pelo Aspergillus niger. Este fato pode ser consequência do ambiente menos favorável ao seu desenvolvimento, levando à hidrólise e disponibilidade de açúcares mais facilmente metabolizados.

A produção de PG começa a partir de $7 \mathrm{~h}$ de fermentação e atinge um pico de atividade igual a $20,9 \mathrm{U} \mathrm{g}^{-1}$ em $66 \mathrm{~h}$ de processo. Santos et al. (2008a) alcançaram, estudando a produção de poligalacturonase por fermentação semi-sólida e utilizando pedúnculo de caju como substrato, $10,1 \mathrm{U} \mathrm{g}^{-1}$ para uma umidade inicial de $40 \%$ e a concentração da fonte de nitrogênio igual a 1\%. Botella et al. (2007) observaram o efeito da umidade inicial e a suplementação com uma fonte de carbono na produção de pectinase e xilanase por Aspergillus awamori, com polpa de uva como substrato. A máxima produção foi de aproximadamente $40 \mathrm{U} \mathrm{mL}^{-1} \mathrm{em} 48 \mathrm{~h}$ de cultivo. Santos et al. (2008b) destacam que a umidade inicial do meio é a variável mais importante para o processo de produção de pectinases.

$\mathrm{O}$ efeito da temperatura e $\mathrm{pH}$ na estabilidade da poligalacturonase do extrato enzimático bruto obtido por cultivo do fungo em 44 h de fermentação, é apresentado na Figura 3.

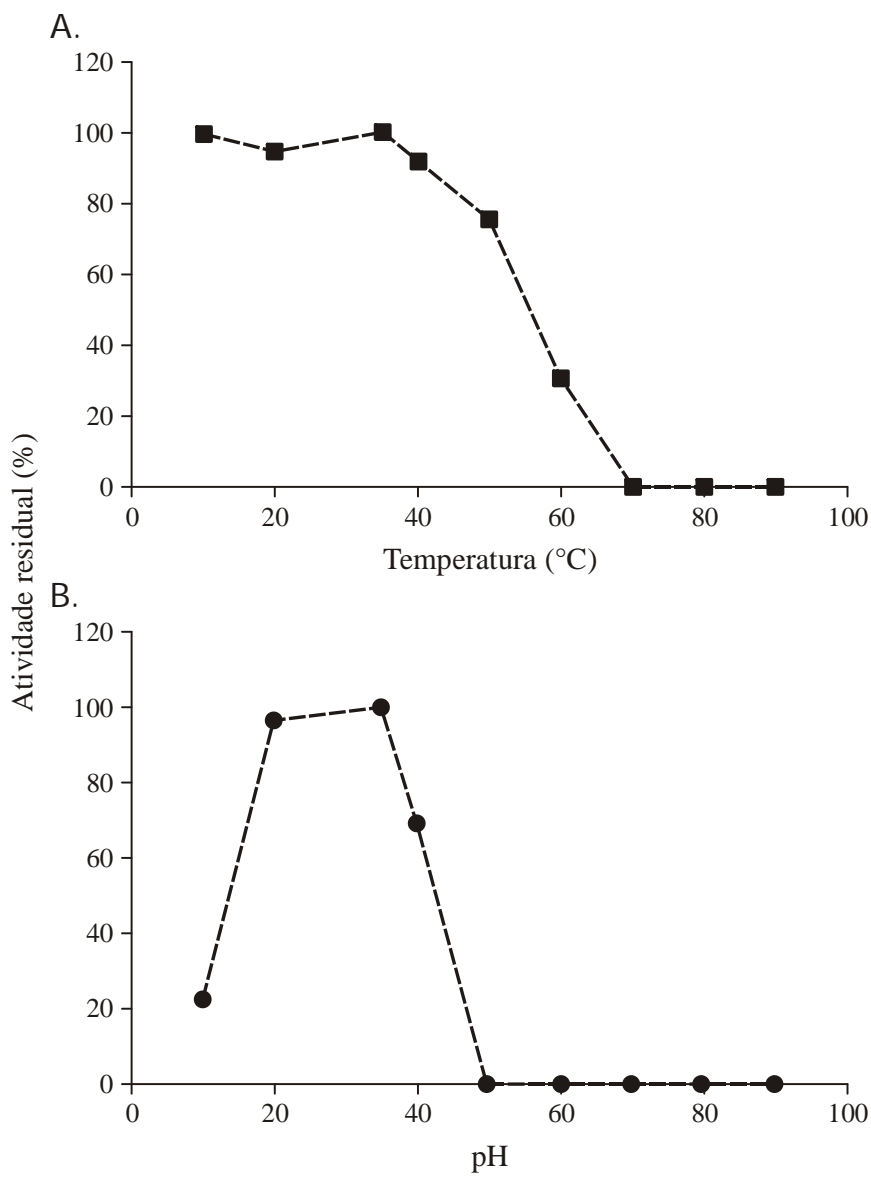

Figura 3. Efeitos na estabilidade da poligalacturonase produzida por FSS quando incubadas (A) durante $20 \mathrm{~min}$ temperatura de $10-90^{\circ} \mathrm{C}$ e, (B) durante $24 \mathrm{~h}$ em tampões com pH variando entre 2,5 a 10,5
A poligalacturonase produzida foi estável até temperaturas de $50{ }^{\circ} \mathrm{C}$, apresentando $75 \%$ da atividade máxima nas condições padrão de $\mathrm{pH} 4,5$ e temperatura de $35^{\circ} \mathrm{C}$. No entanto, foi completamente desativada quando incubada em temperaturas acima de $70{ }^{\circ} \mathrm{C}$, durante $20 \mathrm{~min}$. Esses resultados se aproximam dos encontrados por Zheng \& Shetty (2000), em que a PG produzida apresentou boa termoestabilidade em temperaturas até $50{ }^{\circ} \mathrm{C}$.

A PG mostrou-se estável entre o pH 3,5 e 5,5; no entanto, foi instável em pH acima de 6,5. Zheng \& Shetty (2000) conseguiram uma PG estável ao $\mathrm{pH}$ 6,5 e valores de $\mathrm{pH}$ elevados, acima de 9,0, a enzima tornou-se bastante instável.

Naidu \& Panda (2003) demonstraram que enzimas pectinolíticas presentes no extrato bruto são mais estáveis que enzimas parcialmente purificadas, fato este devido à interação entre outras enzimas e proteínas secretadas pelos microorganismos no meio e/ou combinação dessas duas hipóteses.

Tari et al. (2008) concordam que a poligalacturonase presente no extrato bruto é mais estável do que a enzima purificada e ressaltam, ainda, que caracterizando-se a amostra bruta, percebe-se a ação colaborativa de diferentes enzimas pectinolíticas, pode aumentar o rendimento do processo de extração ou clarificação na indústria de sucos de frutas.

\section{CONCLUSÕES}

1. E possível produzir poligalacturonase utilizando-se o resíduo seco do maracujá, tendo em vista os níveis de pectina e açúcar encontrados nesse substrato

2. Nas condições iniciais de $40 \%$ de umidade e $1,0 \%$ da concentração da fonte de nitrogênio, a atividade de PG alcançou 20,9 $\mathrm{U} \mathrm{g}^{-1}$ após $66 \mathrm{~h}$ de processo.

3. A poligalacturonase produzida apresentou boa estabilidade até temperaturas de $50{ }^{\circ} \mathrm{C}$, apresentando $75 \%$ da atividade máxima a $\mathrm{pH} 4,5$ e temperatura de $35^{\circ} \mathrm{C}$ e estabilidade entre $\mathrm{pH}$ de 3,5 a 5,5.

\section{AGRADECIMENTOS}

Ao CNPq, pelo apoio financeiro.

\section{LITERATURA CITADA}

ABNT - Associação Brasileira de Normas Técnicas. NBR7181, Solo - Análise granulométrica, Rio de Janeiro: ABNT, 1984. 13p.

Abud, A. K. S.; Silva, G. F.; Narain, N. Caracterização de resíduos de indústria de processamento de frutas visando a produção de pectinases por fermentação semi-sólida. In: Simpósio Nacional de Bioprocessos, 16, 2007, Curitiba. Anais... Curitiba: UFPR, 2007. CD-Rom

Alcântara, S. R.; Almeida, F. de A. C.; Silva, F. L. H. da. Emprego do bagaço seco do pedúnculo do caju para posterior utilização em um processo de fermentação semi-sólida. Revista Brasileira de Produtos Agroindustriais, v.9, n.2, p.137-142, 2007. 
Botella, C.; Diaz, A.; Ory, I.; Webb, C.; Blandino, A. Xilanase and pectinase production by Aspergillus awamori on grape pomace in solid state fermentation. Process Biochemistry, v.42, p.98-101, 2007.

Brasil. Métodos físico-químicos para análise de alimentos. 4.ed. Brasília: Ministério da Saúde, 2005. 1015p.

Bueno, M. C.; Peres, M. F. S.; Gattás, E. A. L. Produção de poligalacturonase por três linhagens de Aspergillus isolados do solo. Alimentos e Nutrição, v.16, n.3, p.253-257, 2005.

Correia, R. T. P. Estudo do cultivo semi-sólido de Saccharomyces cerevisiae e Rhizopus oligosporus em resíduo de abacaxi. Natal: UFRN, 2004. 163p. Tese Doutorado

Couri, S.; Farias, A. X. Genetic manipulation of Aspergillus niger for increased synthesis of pectinolytic enzymes. Revista de Microbiologia, v.26, n.4, p.314-317, 1995.

Dartora, A. B.; Bertolin, T. E.; Scandolara C.; Costa, J. A. V.; Silveira, M. M. Estudo comparativo da produção de pectinases por fermentação semi-sólida com diferentes fungos filamentosos. In: Seminário de Hidrólise Enzimática de Biomassas, 6, 1999, Maringá. Anais... Maringá: 1999. CD-Rom.

Fawole, O. B.; Odunfa, S. A. Some factors affecting production of pectic enzymes by Aspergillus niger. International Biodeterioration \& Biodegradation, v.52, p.223-227, 2003.

Fontana, R. C; Salvador, S.; Silveira, M. M. Influence of pectin and glucose on growth and polygalacturonase production by Aspergillus niger in solid-state cultivation. Journal of Industrial Microbiology and Biotechnology, v.32, p.371-7, 2005.

Gummadi, S. M.; Panda, T. Purification and biochemical properties of microbial pectinases: Review. Process Biochemistry, v.38, p.987-996, 2003.

Hölker, U.; Lenz, J. Solid state fermentation - are there any biotechnological advantages? Current Opinion in Microbiology, v.8, p.301-306, 2005.

IBGE - Instituto Brasileiro de Geografia e Estatística. Levantamento sistemático da produção agrícola. <http://www.ibge.gov.br/>. 5 Mar. 2009.

Jayani, R. S.; Saxena, S.; Gupta, R. Microbial pectinolytic enzymes: A review. Process Biochemistry, v.40, n.9, p.2931-2944, 2005.

Kashyap, D. R.; Vohra, P. K.; Chopra, S.; Tewari, R. Applications of pectinases in the commercial sector: A review. Bioresource Technology, v.77, n.3, p.215-227, 2001.

Keey, R. B. Drying of loose and particulate materials. New York: Hemiphere, 1991. 57p.

Martin, N. Isolamento de linhagens fúngicas termofílicas produtoras de pectinases termoestáveis: produção, caracterização e purificação parcial da poligalacturonase. Rio Claro: UNESP, 2006. 65p. Dissertação Mestrado

Miller, G. L. Use of dinitrosalicylic acid reagent for determination of reducing sugar. Analytical Chemistry, v.31, n.3, p.426-428, 1959 .
Naidu, G. S. N.; Panda, T. Studies on pH and thermal deactivation of pectolytic enzymes from Aspergillus niger. Biochemical Engineering Journal, v.16, p.57-67, 2003.

Nicemol J. K. N. Niladevi, G. S. A.; Prema, P. Hydrolysis of pectin: An enzymatic approach and its application in banana fiber processing. Microbiological Research, v.163, p.538-544, 2008.

Otagaki, K. K.; Matsumoto, H. Nutritive values and utility of passion fruit by products. Journal of Agriculture and Food Chemistry, v.6, n.1, p.54-57, 1958.

Pandey, A. Solid-state fermentation. Biochemical Engineering Journal, v.13, n.8, p.81-84, 2003.

Pinto, G. A. S.; Brito, E. S.; Silva, F. L. H. da; Santos, S. F. M.; Macedo, G. R. Fermentação em estado sólido: Uma alternativa para o aproveitamento e valorização de resíduos agroindustriais. Revista de Química Industrial, v.74, n.724, p.17-20, 2006.

Rangana, S. Manual of analysis of fruit and vegetable products. New Delhi: Tata McGraw Hill Publishing Company, 1979. $634 \mathrm{p}$.

Santos, F. M.; Macedo, G. R.; Silva, F. L. H. da; Souza, R. L. A.; Pinto, G. A. Aplicação da metodologia de superfície de resposta no estudo da produção e extração da poligalacturonase. Química Nova, v.31, n.8, p.1973-1978, 2008a.

Santos, S. F. M.; Souza, R. L. A.; Alcântara, S. R.; Pinto, G. A. S.; Silva, F. L. H. da; Macedo, G. R. Aplicação da metodologia de superfície de resposta no estudo da produção de pectinase por fermentação em estado sólido do pedúnculo de caju. Revista Brasileira de Produtos Agroindustriais, v.10, n.2, p.101-109, $2008 \mathrm{~b}$.

Silva, D.; Martins, E. S.; Silva, R.; Gomes, E. Pectinase production by Penicillium viridicatum RFC3 by solid state fermentation using agricultural wastes and agro-industrial by-products. Brazilian Journal of Microbiology, v.33, p.318-324, 2002.

Silva, J. D. Análise de alimentos: Métodos químicos e biológicos. Viçosa: UFV, 1998. 166p

Souza, R. L. A.; Amorim, B. C.; Silva, F. L. H. da; Conrado, L. S. Caracterização do resíduo seco do maracujá para utilização em fermentação semi-sólida. In: Simpósio Nacional de Bioprocessos, 16, 2007, Curitiba, Anais... Curitiba: UFPR, 2007. CD-Rom.

Tari, C.; Dogan, N.; Gogus, N. Biochemical and thermal characterization of crude exo-polygalacturonase produced by Aspergillus sojae. Food Chemistry, v.111, p.824-829, 2008.

Uenojo, M. Produção e caracterização de aromas de frutas por microrganismos pectinolíticos utilizando-se resíduos agroindustriais. Campinas: UNICAMP, 2003. 113p. Dissertação Mestrado

Uenojo, M.; Pastore, G. M. Pectinases: aplicações industrias e perspectivas. Química Nova, v.30, n.2, p.388-394, 2007.

Ustok, F. I.; Tari, C.; Gogus, N. Solid-state production of polygalacturonase by Aspergillus sojae ATCC 20235. Journal of Biotechnology, v.127, p.322-334, 2007.

Zheng, Z.; Shetty, K. Cranberry processing waste for solid state fungal inoculants production. Process Biochemistry, v.33, n.8, p.323-329, 2000. 